\title{
ADOPTION OF SMOKING CHOKOR FOR FISH PROCESSING IN KWARA STATE
}

\author{
J.A. Akangbe, Y. Bankole, B. Ajibola, Researchers \\ Department of Agricultural Extension and Rural Sociology, University of Ilorin, Nigeria \\ Phone: +234-8033-814-003, E-mail: jonesakangbe@gmail.com
}

S.B. Fakayode, J.O. Animashaun, Researchers

Department of Agricultural Economics and Farm Management, University of Ilorin, Nigeria

Phone: +234-803-8550-618, E-mail: reals4u@yahoo.com

\begin{abstract}
This research investigated the adoption of smoking chokor among fish processors in Kwara state, Nigeria. The study made use of structured questionnaire along with interview schedule to a sample size of one hundred and seventy (170) processors randomly selected through a twostage random sampling technique. The data were analyzed with descriptive and inferential statistics and the Regression Analysis. The results obtained through the analysis revealed that $43.7 \%$ of the respondents adopted the improved technology (smoking chokor). A higher percentage of respondents preferred the improved technology for the golden brown colour, fine texture, good smell and delicacy in the taste. The significant determinants of adoption include sex (female), income from fish processing activities $(p<0.05)$ and the trust worthiness of the source of the technology $(p<0.1)$. Perceived benefits associated with technology adoption include wastage reduction, employment generation and the reduction of smoke, while the technicalities associated with the use constitute a major constraint limiting its adoption. The study concludes that fish processors prefer the smoking chokor but its adoption is marred with various constraints. It therefore recommends the need for creating more awareness of the smoking chokor as well as reducing the perceived constraints limiting its adoption by training extension agents and other verifiable sources to educate farmers as they disseminate the technology.
\end{abstract}

\section{KEY WORDS}

Adoption; Value addition; Fish processing; Smoking chokor; Technology.

Fish is a critical source of dietary protein and micronutrients for many isolated communities in rural areas Alamu (2000). Fish may also be the sole accessible and/or affordable source of animal protein for poor households in urban or peri-urban areas. Nutritionally, fish is one extremely important direct source of protein and micronutrients for millions of people in Africa, it contribute indirectly to national food self-sufficiency through trade and exports (Al- Jufaili and Opara, 2006).

Fish is, however, highly susceptible to deterioration without any preservative or processing measures (Clucas et.al., 2002). Al-Jufaili and Opara (2006) reported high incidence of fish losses as a major impediment to the realization of government goal towards increasing the contribution of the sector to the overall national economy. Appropriate processing of fish enables maximal use of raw material and production of value-added products which is obviously the basis of processing profitability. Freshwater fish processing, like the processing of the other food raw materials should: assure best possible market quality, provide a proper form of semi-processed final product, assure health safety of products, apply the most appropriate processing method and reduce wastes to the barest possible extent. Therefore, the development of appropriate fishing machinery and techniques that employed effective production, handling, harvesting, processing and storage, cannot be over-emphasized (Akinneye et al., 2007; Davies, 2005).

One of the major techniques introduced is Smoking Chokor. Smoking Chokor is an improved smoking technology over indigenous method of smoking fish. In 1969, an improved indigenous fish smoking oven - the Smoking Chokor - was introduced into the country. It was developed by FAO and Ghana's Food Research Institute of the Council of Scientific and Industrial Research (CSIR), the Chokor has numerous distinct advantages: it is easy to use, 
has a high capacity, uses little fuel wood, results in shorter smoking time and produces highquality smoked fish.

Given these salient features, the objectives of the present research were to:

- identify the indigenous fish processing technologies available in the study area;

- estimate the factors influencing adoption of smoking-chokor fish processing technology;

- identify the perceived benefits derived from adoption of the improved processing technology;

- investigate possible constraints to adoption of chokor technologies practices.

\section{MATERIALS AND METHODS}

The survey on adoption of smoking chokor by fish processors in Kwara State was carried out using combination of structured questionnaire and interview schedule. Purposive sampling was used to select Edu and Patigi local government in the study area because of the close proximity of their close proximity to river and a high concentration of fishing activities as a livelihood activity of the communities. A -two stage random sampling was employed in the selection of respondents for this study. The first stage involved a simple random selection of 5 villages in each local government and the second stage involved the selection of 17 fish processors from the 10 villages in the study area. A total of 170 respondents were sampled for the study.

Some of parameters investigated by the questionnaire included the socio economics characteristics of fish processors, indigenous technology available in the study area, the benefit and constraints of the technology and the factors influencing adoption of the technology. The data obtained were subjected to descriptive statistics, kruskal-wallis oneway ANOVA, logistic regression and Pearson Product Moment Correlation (PPMC) statistical analysis.

Analytical Technique. Kruscal Wallis one way Analysis of Variance (ANOVA) by ranks. This involved assigning of priorities to perceived benefits and constraint. The equation for extracting the rank is outlined as:

$$
H=\underset{N+1}{12} \Sigma^{1} / n i\left[R i-n i \frac{(N+1)] 2 \ldots \ldots \ldots \ldots \ldots . . .(1),}{2}\right.
$$

where $\mathbf{R} \mathbf{i}$ is the sum of the ranks assigned to observations in the ith sample and $\mathbf{n i} \underline{\mathbf{N}+\mathbf{1})}$ is the expected sum of ranks for the ith treatment.

Logistic Regression:

$$
Y=\beta_{0}+\beta_{1} X_{1}+\beta_{2} X_{2}+\beta_{3} X_{3}+\beta_{4} X_{4}+\beta_{5} X_{5}+\beta_{6} X_{6}
$$

where $Y=$ Adoption of Smoking chokor (taking the value of 1 if respondent adopts and 0 if otherwise); $X_{1}=$ Experience in Fish Processing; $X_{2}=$ sex of respondent; $X_{3}=$ marital status; $\mathrm{X}_{4}=$ Highest educational attainment of respondent; $\mathrm{X}_{5}=$ household size; $\mathrm{X}_{6}=$ income.

\section{RESULTS AND DISCUSSION}

Socio-economic Distribution of Respondents. The result of the distribution of respondents' socio-economic characteristics is presented in Table 1. As revealed in Table 1, $56.3 \%$ of the respondents were females while $43.7 \%$ were males. The highest number of female respondent suggests that processing in this area is mostly practice by females. This is in line with Hibbeln (1995) who stated in his report that majority of the farmers are women and this dominance of women is often attributed to the fact that women continue to bear primary responsibility for household sustenance and well being.

Furthermore, results on Table 1 showed the modal age of the processors to be 3140years while the mean age is 34 . Majority of the processors $74.8 \%$ are married, while very few $16.8 \%$ were single, $6.6 \%$ divorced and $1.8 \%$ widowed. 
Table 1. Distribution of respondents according to their socio-economic characteristics

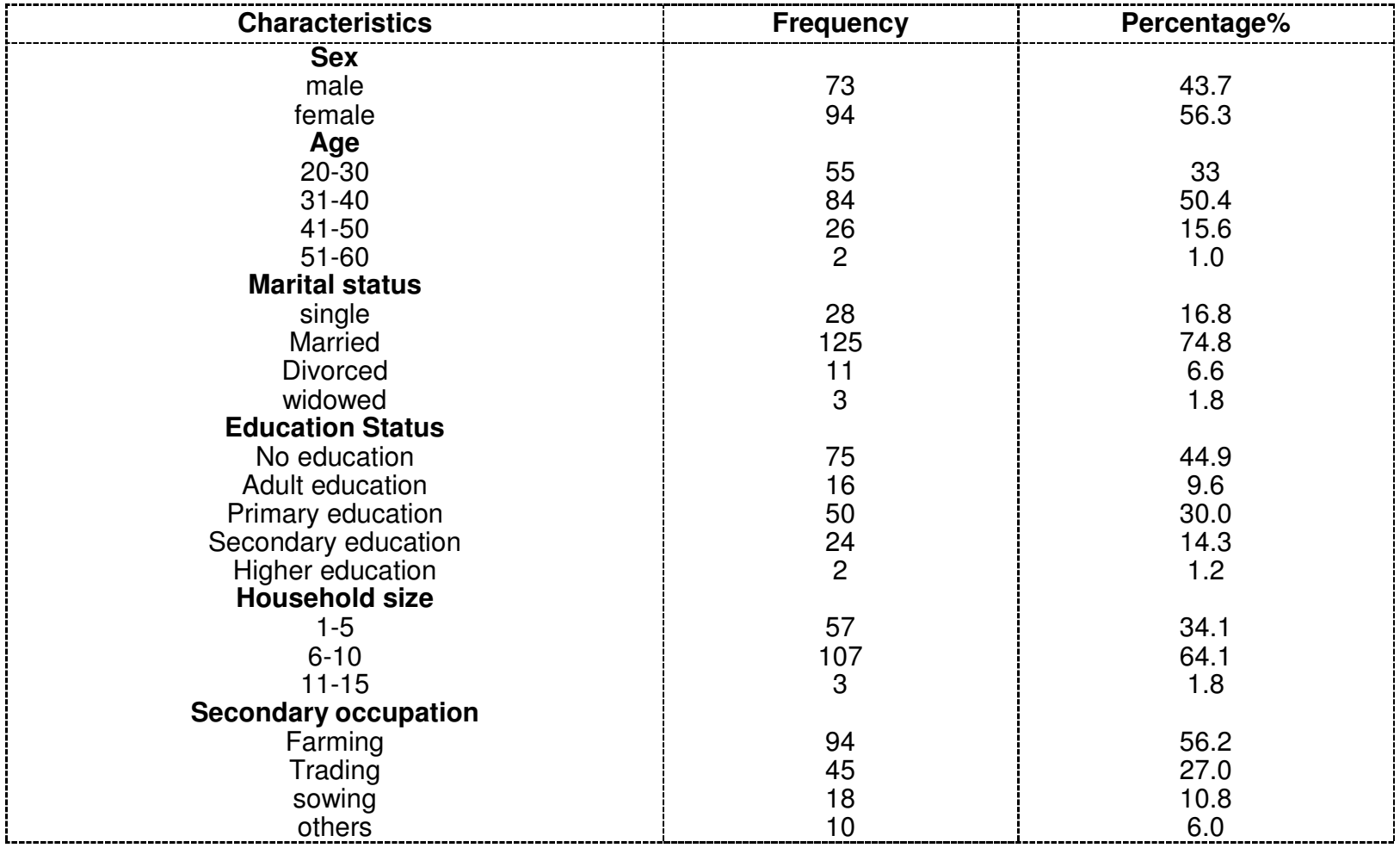

Source: Field Survey, 2012

This reveal that majority of the processors in the study area are married and have children within the range of $6-10(64.1 \%)$. The Tables also revealed that majority of the processors $44.9 \%$ are illiterate (with no formal education) while $30 \%$ are literate having primary education and $14.3 \%$ having secondary education. This implies that present day farmers dispossess some forms of formal education more than half $94 \%$ of the respondents were farmers along with the facts that they are fish processors, while few others trade alongside.

Distribution of the Respondents according to the Use of Indigenous and Improved Method of Fish Processing. The result of the distribution of Respondents based on fish processing techniques adopted is presented in Table 2.

Table 2. Distribution of Respondent According to Fish-Processing Technology Adopted

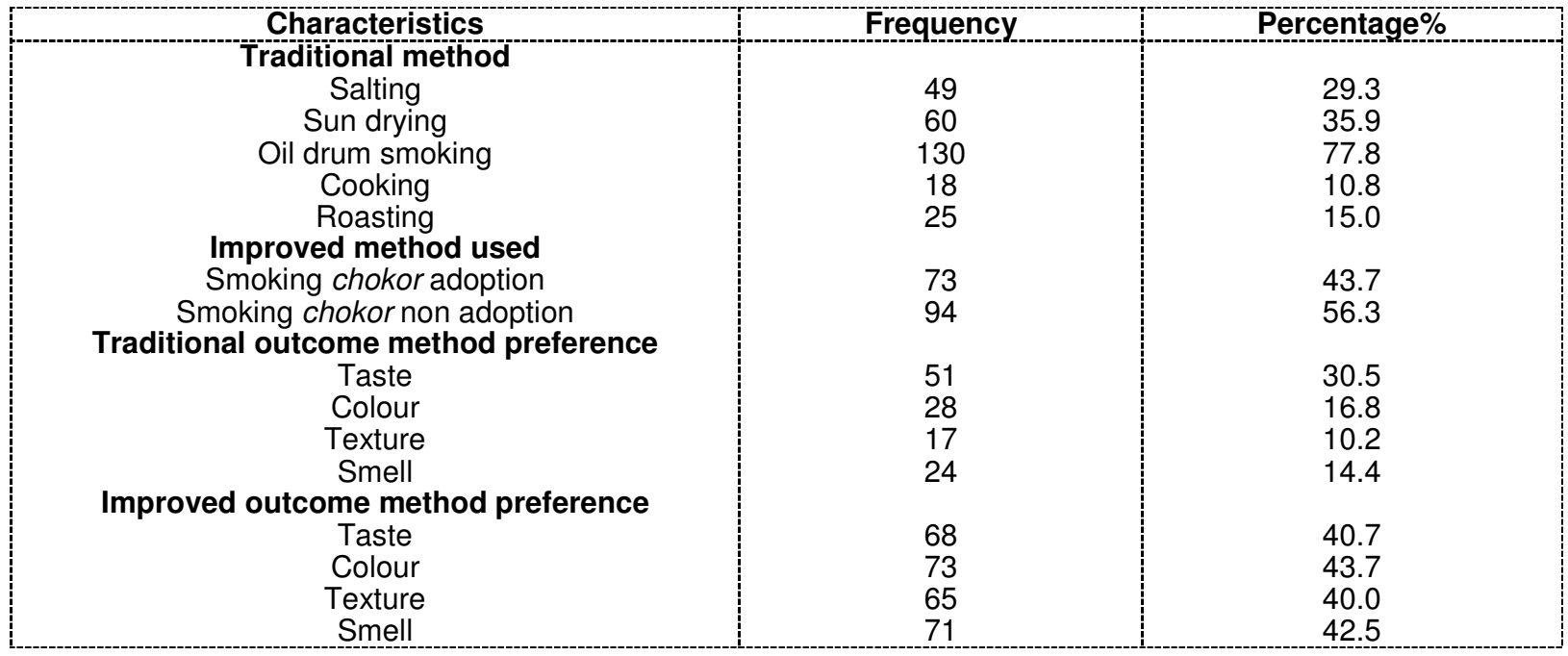

Source: Field Survey, 2012 
Table 2 showed that out of the indigenous methods practiced by the processors, $77.8 \%$ of the respondent used smoking drums, $35.9 \%$ sun drying, $29.3 \%$ use salting, $10.8 \%$ cooking and $15.0 \%$ roasting. It was observed that $43.7 \%$ of the respondents adopted the improved technology (smoking chokor) while majority have not adopted it. The outcome of fish preference viewed by the respondents, higher percentage of respondents preferred the improved technology and out of the listed preferences, $43.7 \%$ preferred it for the golden brown colour, $40.7 \%$ for the taste, while $40.0 \%$ preferred it for its texture and smell.

Factors influencing adoption of improved value added technology. Various factors were hypothesized as factors influencing fish processors adoption of improved technology. The result of the significant factors influencing the adoption of chokor technology by respondents in the study area is presented in Table 3.

Table 3. Logistic Regression Results indicating factors influencing adoption of Smoking Chokor fish processing technology

\begin{tabular}{|c|c|c|c|c|c|}
\hline Variable & B & S.E & Df & Sig & Exp \\
\hline Processing Experience & 0.103 & 0.133 & 1 & 0.440 & 1.108 \\
\hline Gender (Female) & -1.132 & 0.386 & 1 & $0.003^{\star * *}$ & 0.322 \\
Marital status & 0.920 & 0.604 & 1 & 0.128 & 2.509 \\
Education & -0.068 & 0.199 & 1 & 0.734 & 0.934 \\
Household size & -0.182 & 0.113 & 1 & 0.106 & 0.833 \\
Income & 0.000 & 0.000 & 1 & $0.014^{\star *}$ & 1.000 \\
Source (Agency) & 0.445 & 0.253 & 1 & $0.079^{*}$ & 1.560 \\
Constant & -0.980 & 1.934 & 1 & 0.612 & 0.375 \\
\hline
\end{tabular}

Model Chi-square: 35.224

2 log likelihood for the model: 196.138

Overall case corrected predicted: $70.1 \%$

Note: single and triple astericks indicate significance of co-efficient at10 and $5 \%$ p-value.

As revealed in the Table, being a female, Income from Fish processing and agent responsible for the provision of the fish processing technology were all significant variables explaining the variation in the level of adoption of the technology (Table 3).

Specifically at a p-value of 0.05 , being a female and earning a relatively high income fom fish processing activities increase the chance of adopting the chokor fish processing technology. Furthermore, at a p-value of 0.1 the source of the technology positively influenced the probability of adoption of the chokor technology.

Perceived Benefits Derived from the Adoption of Improved Value Added Technology. Result of kruskal-wallis one-way analysis of variance (ANOVA), ranking the benefits derived from the adoption of the improved value added technology is presented in Table 4.

Table 4. Perceived Benefits derived from Adoption of Chokor fish processing technology

\begin{tabular}{|c|c|c|}
\hline Benefits & Mean Rank & Rank \\
\hline Lessening of drudgery of fish smoking activity & 592.15 & 4 \\
\hline Better quality of fish smoked & 619.75 & 6 \\
Reduction of smoking nuisance & 587.63 & 3 \\
Increase in capacity of fish smoked & 601.21 & 5 \\
Increase in income from sales & 625.78 & 1 \\
Wastage reduction & 526.06 & 2 \\
\hline Employment & 542.42 & 1 \\
\hline
\end{tabular}

Chi-square $\left(x^{2}\right)$ : 14.291; Df: 6; Asymp. Sig: 0.27

1-7 Lowest to highest.

Source: field source, 2012

Table 4 shows the ranking of benefits for the respondent. These results show that the respondents perceived benefits of the use of chokor technology do not differ significantly from the hypothesized values. (chi-square with six degrees of freedom $=14.29, p=.270$ ). Specifically, respondents perceived benefits ranked highest were wastage reduction followed by employment generation and the reduction of smoke. 
Constraints Militating against the Adoption of Improved Value Added Technology. The result of kruskal-wallis one-way analysis of variance (ANOVA), ranking the constraints militating against the adoption of improved value added technology is presented in Table 5.

Table 5. Rank of Perceived constraints against the Adoption of Chokor Technology

\begin{tabular}{|c|c|c|}
\hline Constraints & Mean Rank & Rank \\
\hline No interest & 572.59 & 6 \\
Difficult to use & 750.61. & 1 \\
Problem of fishing season & 318.63 & 4 \\
Insufficient fish to process & 685.31 & 5 \\
Inadequate source of power & 706.71 & 3 \\
Problem of middle men & 632.37 & 7 \\
\hline
\end{tabular}

Chi-square( $\left.x^{2}\right)$ : 247.206; Df: 7; Asymp. Sig: 0.000

1-7 Lowest to highest.

Source: field source, 2012

The data analysis on Table 5 shows the ranking of constraints militating against adoption of improved value added technology. All the respondents constraints were indicated as significantly different from the hypothesized values $\left(\mathrm{chi}^{2}\right.$ is $\left.247.206 ; \mathrm{p}<0.005\right)$.

\section{CONCLUSION AND RECOMMENDATION}

Conclusively, this study ascertained that about $43 \%$ of the fish processors in the study area adopted smoking chokor and some of the perceived benefits associated with its adoption include wastage reduction followed by employment generation and the reduction of smoke. Major perceived constraints identified as militating against the technology adoption were the difficulty in use and the technicalities involved in the use. The major determinants of the technology adoption variation among respondents include female gender, income from fish processing and the source of the fish processing technology.

In view of these, this study recommends that smoking chokor beneficiaries (respondents) should create awareness to non-beneficiaries so that every processors can have interest in using it and will also be aware of the benefits derived from using the technology. Provision of chokor technology through reliable and trust worthy agents to endusers.

\section{REFERENCES}

[1] Akinneye, J.O., I.A. Amoo and S.T. Arannilewa., 2007.Effect of drying methods on the nutritional composition of three species of (Bonga sp., Sardinella sp. and Heterotis niloticus). J. Fish. Int., 2(1): 99-103. Asian J. Agric. Sci., 3(6): 427-436, 2011435

[2] Alamu, S.,2000. Assessment of women contribution to fishing industry and fishmarketing in Kainji Lake Basin. Annual Report, pp: 184-190.

[3] Al-Jufaili, M.S. and L.U. Opara, 2006. Status of fisheries postharvest industry in the Sultanate of Oman: Part1 handling and marketing system of fresh fish. J. Fish. Int., 1(2-4): 144-149b.

[4] Clucas, I.J. (2002) Fish handling, preservation and processing in the tropics, part 2 report of the Tropical Development and Research Institute, G145

[5] Davies, R.M., 2005. Development of Appropriate Technology of fish processing in Nigeria. A paper presented at a one-day workshop on intensive fish farming on Thursday, 24th February.

[6] Hibbeln, J.R. and Salem, N. (1995) Dietary polyunsaturated fatty acids and depression: when cholesterol does not satisfy. American Journal of Clinical Nutrition, 62. 